${ }^{2}$ Schneider RC, Thompson JM, Bebin J. The syndrome of acute central cervical spinal cord injury. $J$ Neurol Neurosurg Psychiatry 1958;21:216-27.

${ }^{3}$ Byers RK. Transection of the spinal cord in the newborn. A case with autopsy and a comparison with a normal cord at the same age. Arch Neurol Psychiat 1932;27:585-92.

${ }^{4} \mathrm{~K}$ ock BM, Eng GM. Neonatal spinal cord injury. Arch Phys Med Rehabil 1979;60:378-81.

${ }^{5}$ Pang D, Wilberger JE. Spinal cord injury without radiographic abnormalities in children. $J$ Neurosurg 1982;57:144-49.

Accepted 25 June 1984

\section{Relapse of benign partial epilepsy of children in adulthood: report of a case}

Sir: Benign partial epilepsy of children with rolandic EEG foci, also called rolandic epilepsy, has a good long-term prognosis. ${ }^{1}$ Epileptic seizures disappear spontaneously and never occur after 16 years of age. ${ }^{2}$ We report a case of relapse in adulthood.

A thirty-year-old, right handed man has no family history of epilepsy. At the age of $10 \mathrm{yr}$ he had his first seizure, characterised by jerks involving the left arm and the left face. Later fits were rare and mainly occurred during sleep until the age of $13 \mathrm{yr}$, when secondary generalisation occurred on two occasions. EEG performed when aged $11 \mathrm{yr}$ showed rolandic discharges. Right carotid angiography was normal. He was seizurefree from 13 to $21 \mathrm{yr}$ of age and without anticonvulsant therapy from $15 \mathrm{yr}$ of age. At the age of 21 , he began to have seizures with similar characteristics, often followed by secondary generalisation until aged $28 \mathrm{yr}$; thereafter he had only simple motor seizures affecting the left upper limb with a frequency of one to four per month. Right carotid angiography performed at 21 years of age, and an enhanced CT scan performed at $30 \mathrm{yr}$ of age, were normal as was the neurological examination. An EEG performed at $30 \mathrm{yr}$ of age showed a right rolandic focus (fig). The features of epilepsy of our patient in childhood are those observed in typical rolandic epilepsy: seizures began at school age, were mainly focal motor in type and rare in occurrence, were sleep related and disappeared at puberty. EEG showed rolandic discharges. Neurological and neuroradiological findings were normal. After a seizure-free period of 8 $\mathrm{yr}$, he relapsed, with epilepsy similar to that of his childhood.

Recurrence in adulthood of isolated gen-
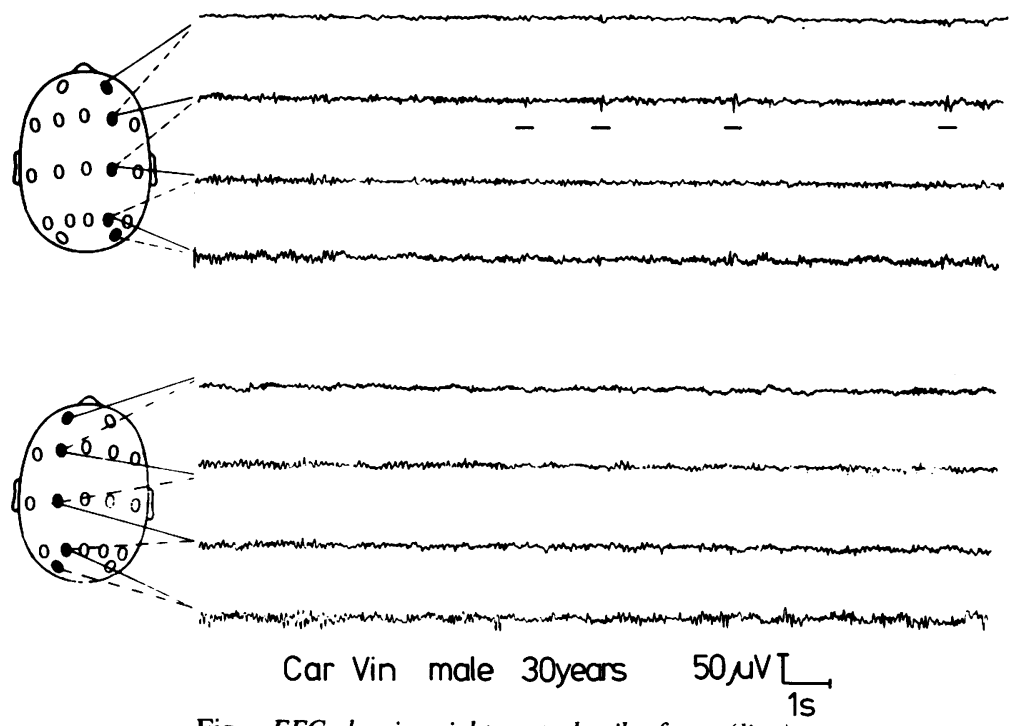

Fig. EEG showing right central spike focus (line)

eralised convulsive seizures in patients who have suffered from rolandic epilepsy in childhood has been reported ${ }^{3}$ as a later manifestation of convulsive predisposition. This does not seem to be the case in our patient who had an electroclinical picture similar to that observed in his childhood when the association of partial motor seizures and rolandic discharges is characteristically found. ${ }^{4}$ Recurrence of epileptic seizures after a long seizure-free period is thus possible in focal "functional" epilepsies. The good prognosis of rolandic epilepsy is not invalidated by our case report. When seizures relapse without apparent aetiological factors in a patient with previous benign partial epilepsy, further neuroradiological examination is not necessary in the absence of neurological deficit and with normal CT scan findings.

\section{GIOVANNI AMBROSETTO PAOLO TINUPER AGOSTINO BARUZZI Istituto di Clinica Neurologica, Via Ugo Foscolo, 7 40123 Bologna, Italy}

\section{References}

${ }^{1}$ Blom S, Heijbel J. Benign epilepsy of children with centrotemporal EEG foci: a following-up study in adulthood of patients initially studie $\stackrel{\vec{\rho}}{\stackrel{P}{0}}$ as children. Epilepsia 1982;23:629-32. ㄱ. ${ }^{2}$ Loiseau P, Pestre M, Dartigues JF, Commentes D, Barberger-Gateau C, Cohadon S. Langg term prognosis in two forms of childhథ®巿 epilepsy: typical absence seizures and epilopsywith rolandic (centrotemporal) EEG foci. tor (⿹ Neurol 1983;13:642-8.

${ }^{3}$ Beaussart M. Crises epileptiques aprés guerißor, d'une EPR (épilepsie a paroxys rolandiqués). Rev Electroencephalagr Neurophysiol Clin 1981;11:489-92.

${ }^{4}$ Heijbel J, Blom S, Rasmuson M. Benign epilepsy of childhood with centrotemporal EEG foci: $\dot{ }$ genetics study. Epilepsia 1975;16:285-93.

Left temporal lobe abscess presenting with? an acute amnesic syndrome 28 years after contralateral temporal lobe abscess

Sir: The amnesic syndrome can result from 3 bilateral damage to the hippocampus and temporal lobes. We describe a syndromeo similar to transient global amnesia as the presenting symptoms of a left temporale lobe abscess in a man whose contralateral temporal lobe had been damaged twenty-0ㅡㅡ eight years earlier by an abscess and its surgical removal.

A 33-year-old left-handed man pre sented to the casualty department witho 